\title{
Emergência de sândi consonântico em Português Europeu: uma abordagem prosódica
}

\author{
Alexandra Malho \\ Centro de Linguística, Faculdade de Letras, Universidade de Lisboa \\ Susana Correia \\ Centro de Linguística, Faculdade de Ciências Sociais e Humanas, Universidade Nova de \\ Lisboa \\ Sónia Frota \\ Centro de Linguística, Faculdade de Letras, Universidade de Lisboa
}

\begin{abstract}
:
In European Portuguese, the domain for sandhi phenomena is the intonational phrase. Unlike the intonational phrase, the phonological phrase has been shown to be only relevant for rhythm and prominence-related phenomena (Frota, 2000, 2014). Fricative voicing between words (casa[3b]rancas, casa[jp]retas) and ressylabification before vowel-initial words (casa[ze]marelas) occur within the intonational phrase. In this study, we considered spontaneous productions of a Portuguese child (Luma), aged 2;04-4;00, to examine the acquisition of external consonantal sandhi. The data show that sandhi production varies according to the segmental $(\mathrm{C \# C}, \mathrm{C \# V}, \mathrm{CFric}$, CVib, CLat) and prosodic context (clitic, prosodic word, position in prosodic structure). The data further confirm that sandhi occurs within the intonational phrase, supporting the analysis proposed for the adult grammar. This study contributes to the understanding of the relationship between the acquisition of the prosodic structure and the acquisition of sandhi phenomena.
\end{abstract}

Keywords: sandhi, acquisition, prosodic structure, Coda.

Palavras-chave: sândi, aquisição, estrutura prosódica, Coda.

\section{Introdução}

O sândi pode ser definido como “(...) the merging of two words or word forms and the resulting systematic phonological changes. (...) External sandhi takes place between two consecutive words" (Bussmann et al., 2013). Podemos encontrar exemplos de sândi externo em línguas como o Inglês (ex.: a book [əbvk]/an egg [ænعg]) e o Francês, língua em que o

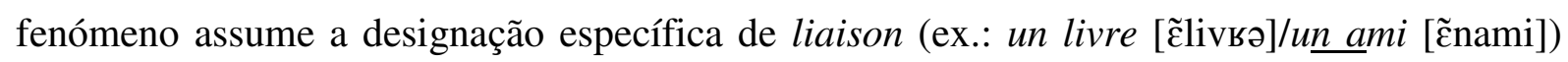
(Wauquier \& Shoemaker, 2013). Os fenómenos de sândi externo são frequentes nas línguas românicas, o que parece relacionar-se com o facto de não existir isomorfismo entre os domínios morfossintático e prosódico (Ledgeway \& Maiden, 2016) e, nomeadamente, com o facto de a palavra prosódica não delimitar o sândi nestas línguas (Vigário, 2003). Esta abundância de 
fenómenos de sândi nas línguas românicas pode ainda relacionar-se com a estrutura silábica destas línguas, já que parece haver uma correlação entre uma estrutura silábica mais simples (como a que se observa nas línguas Românicas, por exemplo, em comparação com as línguas Germânicas) e a ressilabificação (Peperkamp, 1997), pois esta última tende a otimizar sequências silábicas mais simples (e.g. CVC > CV).

Em Português Europeu (PE), o fenómeno em estudo pode ocorrer nos seguintes contextos (Frota, 2000):

(1) V\#V - $\underline{\mathbf{a}}$ alun $\underline{\mathbf{a}}$ aceitou, em que [e $\mathrm{e}]$ passa a [a], quando a vogal (V) final de palavra é seguida de palavra iniciada por $\mathrm{V}$;

(2) C\#C - lápis branco ['lapiz'brẽ̂ku] / lápis preto ['lapif'pretu], onde se verifica, por parte da consoante (C) em Coda, a assimilação do vozeamento da consoante que inicia a palavra seguinte;

(3) $\mathrm{C} \# \mathrm{~V}$ - lápis azul ['lapize'zuł], exemplo no qual existe uma ressilabificação, passando a $\mathrm{C}$ em Coda para Ataque da sílaba seguinte.

Para além dos processos de resolução de adjacência de vogais (V\#V), tais como a crase, o apagamento da vogal anterior e a semivocalização, e dos fenómenos de assimilação de vozeamento $(\mathrm{C \# C})$ e de ressilabificação $(\mathrm{C \# V})$, os fenómenos de sândi incluem ainda a haplologia. A haplologia ocorre quando, numa sequência de palavras, a última sílaba da primeira palavra é idêntica ou muito semelhante à sílaba inicial da palavra seguinte, como se ilustra no exemplo (4) (Frota, 2000):

(4) campo pequeno - cam[p]equeno.

A realização de sândi relaciona-se com a estrutura prosódica em $\mathrm{PE}$, dado que o sândi é tipicamente bloqueado em fronteira de Sintagma Entoacional (IP), como ilustrado em (5) e (6) (Frota, 2014:14.).

(5) $[\mathrm{a}[\mathrm{z}]$ aluna[z] obtiveram boa[z] avaliaçõe[J]]IP

(6) $[\mathrm{a}[\mathrm{z}]$ aluna[z] estrangeiras no[z] Açore[J]]IP [até onde sabemo[J]]IP [aceitaram vir]IP 
$\mathrm{Na}$ aquisição, a realização de sândi externo consonântico está relacionada com o desenvolvimento do constituinte silábico Coda (Jordão \& Frota, 2010). Até este constituinte emergir, não será possível atestar a produção de sândi nem tomá-la como um indício revelador do desenvolvimento do fraseamento prosódico. Freitas (1997) e Correia (2004) referem que a consoante fricativa (CFric) é adquirida mais precocemente em Coda quando comparada com as consoantes líquidas (CLíq), mas a sua análise apenas tem em consideração os constituintes sílaba e palavra, não abordando a restante estrutura prosódica. Na realidade, a palavra tratada por estas autoras é a palavra lexical e não a palavra prosódica, uma vez que não se tem em conta, por exemplo, o número de proeminências ou se existe acento tonal.

Uma análise do processo de aquisição da Coda considerando todo o enunciado produzido pela criança permite uma perspetiva do desenvolvimento do fenómeno de sândi. De facto, os constituintes superiores à sílaba parecem desempenhar um papel relevante para a aquisição da Coda, já que a aquisição da Coda pode depender de condições determinadas em níveis superiores da estrutura prosódica (Jordão, 2009; Jordão \& Frota, 2010). Estas autoras destacam a posição final de IP como elemento determinante para a realização do segmento em Coda. Assim, para além de confirmarem a aquisição mais precoce em Coda de CFric em relação a CLíq, estes estudos mostram a relevância da fronteira final de IP na emergência da consoante em posição de Coda, uma vez que a fronteira deste constituinte prosódico, uma posição especialmente proeminente na língua, explica 92\% das Codas realizadas, como ilustrado em (7) e (8) (Jordão 2009:65).

(7) ['oKeupe'tinu $]]-[[($ olha $) \omega] \Phi[($ os $($ patinhos $) \omega) \omega] \Phi] I$ (Luma: 3;03)

(8) [upe'tipupiki' ninuf] - [[(os (patinhos) $\omega) \omega] \Phi[($ pequeninos $) \omega] \Phi] \mathrm{I}($ Luma: 3;03)

Estudos recentes sobre o fraseamento prosódico inicial levantam a hipótese de que a aquisição da estrutura prosódica se baseia num processo de "desdobramento" de níveis prosódicos ("unfolding hypothesis") e sugerem que este fraseamento evolui em três etapas: primeiro, a produção de unidades prosódicas está limitada a IPs de uma palavra prosódica (PW) constituída por uma única sílaba; em seguida, o IP pode ser constituído por uma PW com mais do que uma sílaba; finalmente, o IP passa a abranger mais do que uma PW, tal como no discurso 
do adulto. Fenómenos como o truncamento, a distribuição do acento tonal e das pausas, bem como a entoação, suportam este padrão de desenvolvimento (Frota et al., 2016). Nesta linha, e dado que o fenómeno de sândi externo implica não só a combinação de palavras, logo um MLUw > 1,5 (MLUw refere-se à medida média do enunciado em palavras), mas também palavras prosodicamente fraseadas no mesmo IP (etapa 3), espera-se que, aquando da produção de combinação de palavras e da emergência de sândi, a criança comece a evidenciar um fraseamento prosódico de acordo com a gramática do adulto, isto é, que o domínio para o sândi seja o IP.

Os estudos de aquisição da estrutura prosódica são cruciais para compreender a forma como uma criança se desenvolve linguisticamente em contacto com um sistema-alvo. Esperase que os dados sobre a aquisição de fenómenos de sândi possam fornecer pistas para avançar e aprofundar a nossa compreensão sobre o desenvolvimento prosódico da criança.

Através do estudo aqui realizado, pretende-se, então, compreender:

(i) Quando emerge o sândi externo consonântico e quando pode ser considerado adquirido?

(ii) A emergência de sândi acontece em simultâneo em ambos os contextos C\#C e $\mathrm{C \# V}$ ?

(iii) Qual o papel dos vários constituintes prosódicos em posição medial de IP na emergência do fenómeno de sândi?

(iv) Em que medida é que a emergência de sândi revela aspetos do desenvolvimento da estrutura prosódica?

O sândi funciona como evidência para a organização da estrutura prosódica em PE, já que a fronteira de IP bloqueia a realização deste fenómeno. Importa, pois, perceber como evolui o fraseamento prosódico da criança e em que medida o estudo do sândi nos permite conhecer melhor o processo de desenvolvimento da estrutura prosódica.

\section{Metodologia}

Neste ponto, serão explicitados os aspetos metodológicos adotados no presente estudo. Assim, esta secção fornece informação sobre o tipo de estudo realizado (2.1.) e o corpus utilizado (2.2.). 


\subsection{Tipo de estudo}

Para encontrar resposta para as questões de investigação, foi feito um estudo descritivo com base no desenvolvimento linguístico infantil. Este estudo de caso é de tipo longitudinal e baseia-se em produções espontâneas de uma criança portuguesa (Luma), observada em vários estádios de desenvolvimento (a mesma criança estudada em Jordão, 2009 e Jordão \& Frota, 2010). O período selecionado para análise tem início nos 2;04 e vai até aos 4;00. A opção de começar a análise de dados aos 2;04 prende-se com o facto de as condições mencionadas anteriormente (MLUw > 1,5 e palavras prosodicamente fraseadas no mesmo IP) só se verificarem a partir sensivelmente desta idade, tornando irrelevantes para o estudo em causa dados anteriores. A janela temporal estudada foi definida, igualmente, com base no processo de aquisição dos segmentos em Coda, pretendendo-se abarcar o momento da sua emergência e a sua estabilização, de modo a que seja possível verificar a evolução do processo de aquisição.

\subsection{Corpus}

O Corpus é constituído por um total de 7083 enunciados. Desses enunciados, 4144 referem-se a fronteiras internas de IP e 2939 apresentam dados relativos ao final de IP. Uma parte destes enunciados foi extraída de três bases de dados já existentes e que foram construídas com recurso a diferentes metodologias. Os dados do diário parental vêm complementar os dados extraídos de gravações áudio e vídeo:

(i) LumaLiDaOn - diário parental (http://labfon.letras.ulisboa.pt/LumaLiDa.htm)

(ii) LumaLiDaAudy - áudio (http://labfon.letras.ulisboa.pt/lumalidaaudy.htm)

(iii) LumaLiDaVideo - vídeo (http://www.clul.ul.pt/pt/investigacao/159acquisition-in-european-portuguese-resources-and-results).

Outra parte dos dados foi transcrita no âmbito do presente estudo, resultando numa nova base de dados construída com recurso à ferramenta Phon (https://www.phon.ca/phontrac). Para além de ter sido elaborada para cada enunciado a transcrição ortográfica e fonética do alvo e da produção da criança, foi ainda introduzida uma fiada na qual se anotou a prosodização dos enunciados através de uma codificação numérica, o que permitiu o alinhamento da Coda (alvo) com os vários constituintes prosódicos. Para esta codificação, utilizaram-se os critérios definidos em Jordão (2009) e na anotação prosódica das bases de dados LumaLiDaOn e 
LumaLiDaAudy. As transcrições e codificações foram verificadas e validadas por um segundo investigador. A silabificação efetuada automaticamente pelo software Phon foi integralmente revista de forma manual e corrigida de acordo com a estrutura silábica do PE.

Os enunciados contidos nas quatro bases de dados foram, posteriormente, compilados num ficheiro Excel e organizados por idades (mensalmente), natureza do segmento em Coda

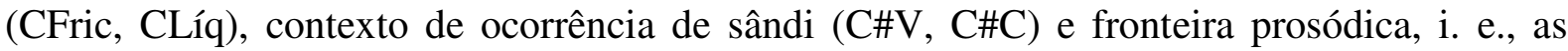
fronteiras entre clítico $(\mathrm{Cl}$.) e $\mathrm{PW}$, entre $\mathrm{PWs}$, entre sintagmas fonológicos $(\mathrm{PhP})$ ou a fronteira de IP.

As estratégias de reparação usadas, amplamente analisadas em Jordão (2009) e Jordão \& Frota (2010), foram, também, assinaladas para análise posterior.

Alguns enunciados com Coda presente no alvo foram excluídos de acordo com os seguintes critérios (largamente adotados de Jordão, 2009):

(i) Utilização de palavras não-nativas;

(9) Toys're Us - ['tojza'rez]

(Luma: 3;04)

(ii)Presença de sequências de duas palavras com segmentos adjacentes semelhantes ${ }^{1}$;

(10) Podem todos jogar. - ['podẽ̃y' toduzu'gali]

(Luma: 3;02)

(iii) Existência de discurso/segmentos ininteligível/is;

(11) Dos barquinhos. - [du*be'kinuf]

(Luma: 3;09)

(iv) Falta de correspondência entre a transcrição ortográfica do alvo e a produção real da criança, onde o mesmo contexto potencial de sândi não ocorre.

(12) Nunca mais vi a tia Guida. - ['nũke' vie' tie 'gide]

(Luma: 2;09)

\footnotetext{
${ }^{1}$ Devido à coincidência de traços nos segmentos em análise, não é possível determinar se estamos perante um caso de sândi com presença de assimilação de vozeamento por parte do segmento em Coda ou perante um caso de não produção de Coda. 


\section{Resultados}

Os dados analisados mostram que a aquisição do sândi varia de acordo com o segmento em Coda, com o contexto segmental e com a fronteira prosódica. Assim, no ponto 3.1., serão apresentados dados relativos ao fenómeno de sândi tendo em consideração o segmento que preenche a posição de Coda. Em 3.2., abordar-se-á a variação que decorre do contexto segmental em que o sândi ocorre e, em 3.3., a variação que resulta da fronteira prosódica em causa. Finalmente, no ponto 3.4., far-se-á a comparação entre o processo de aquisição da Coda em posição medial de IP e em posição final de IP.

\subsection{Segmento em Coda}

A figura 1 mostra que a aquisição do sândi se desenvolve de forma diferenciada quando olhamos para a qualidade do segmento em Coda, isto é, assiste-se a uma evolução distinta quando estamos perante uma CFric ou uma CLíq, não tendo em consideração o contexto C\#C ou C\#V ou o contexto prosódico.

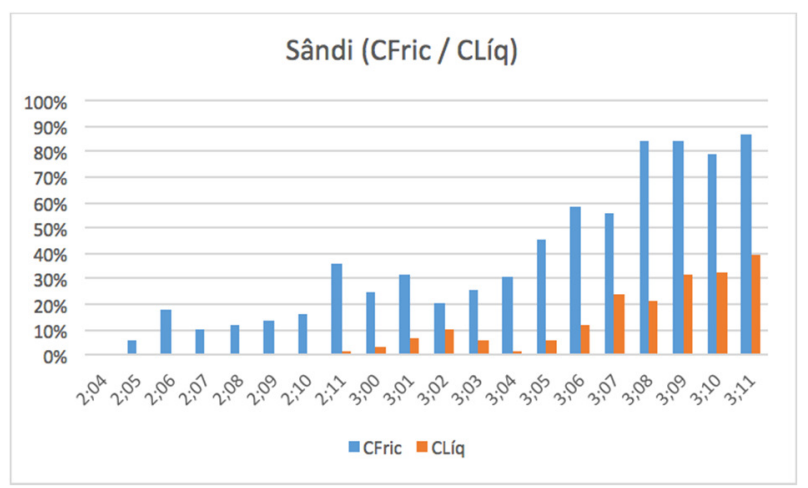

Figura 1: Desenvolvimento do sândi em função da natureza do segmento em posição final de palavra. Percentagem de ocorrência em relação à totalidade dos alvos registados em cada período.

De acordo com a análise da figura 1, verificamos que o sândi se desenvolve mais precocemente com CFric do que com CLíq, sendo possível estabelecer a seguinte ordem de emergência: CFric $(2 ; 05)$ > CLíq (3;00), o que está em linha com os resultados apresentados por Jordão (2009) para a mesma criança e com a própria ordem de aquisição dos segmentos em Coda referida em outros estudos, para o Português Europeu (Freitas, 1997; Correia, 2004). 


\subsection{Contexto de sândi}

Na figura 2, pode observar-se a evolução do processo de aquisição de sândi em função do contexto segmental $(\mathrm{C \# V}$ e $\mathrm{C \# C})$. Os dados reúnem todas as produções de sândi correspondentes a qualquer um dos segmentos em Coda (CFric ou CLíq), divididos de acordo com o segmento que inicia a palavra seguinte (vogal ou consoante).

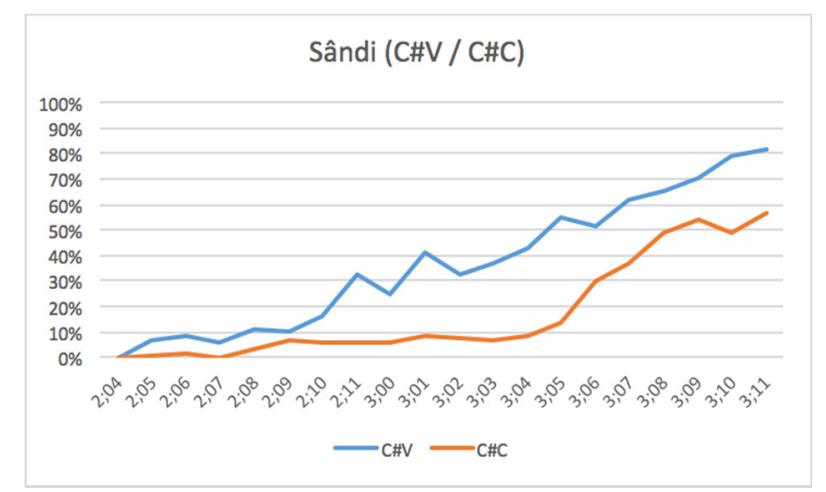

Figura 2: Desenvolvimento do sândi em função do contexto segmental, ou seja, da natureza do segmento em posição inicial da palavra. Percentagem de ocorrência em relação à totalidade dos alvos registados em cada período.

Podemos verificar que, independentemente do segmento em Coda, o sândi em contexto $\mathrm{C \# V}$ emerge mais cedo e apresenta uma linha de desenvolvimento consistentemente mais avançada quando comparado com o contexto C\#C. O sândi em contexto C\#C depende, efetivamente, do facto de a criança ter adquirido o constituinte Coda, enquanto o sândi em contexto C\#V apresenta a produção de uma consoante em posição de Ataque silábico, ou seja, no início da palavra seguinte. Parece ser, assim, claro o impacto da aquisição da Coda no desenvolvimento do sândi C\#C, que emerge mais tardiamente e apresenta uma expressividade menor ao longo do período estudado.

\subsection{Constituinte prosódico}

Na figura 3, estão presentes os dados relativos às produções de sândi organizadas por contexto prosódico (Cl./PW, PW/PW e PhP/PhP). Uma vez mais, todos os segmentos em Coda foram agrupados, sendo a fronteira prosódica a única variável aqui observada. 


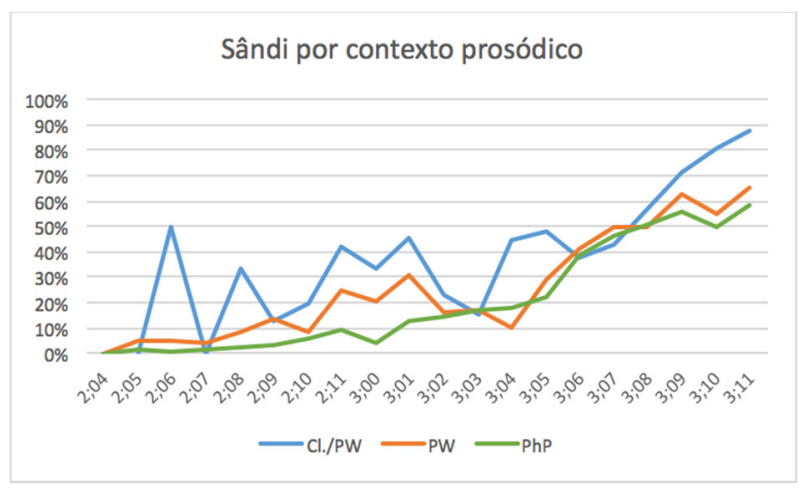

Figura 3: Desenvolvimento do sândi em função do contexto prosódico, ou seja, da natureza da fronteira prosódica entre as duas palavras. Percentagem de ocorrência em relação à totalidade dos alvos registados em cada período.

Esta perspetiva longitudinal evidencia que a emergência de sândi em contexto Cl./PW é mais precoce e mantém valores de produção mais elevados praticamente ao longo de todo o período estudado. A fronteira PW/PW favorece a emergência do fenómeno relativamente à fronteira de $\mathrm{PhP}$, contudo, a partir dos 3;05, as produções correspondentes a estes contextos prosódicos (PW/PW e $\mathrm{PhP} / \mathrm{PhP})$ apresentam valores equivalentes, aproximando-se, igualmente, do contexto Cl./PW. Estes dados corroboram a hipótese de Frota et al. (2016) de que a aquisição da estrutura prosódica se baseia num processo de "desdobramento" de níveis prosódicos ("unfolding hypothesis"), pois o contexto Cl./PW pode ser interpretado como um contexto prosodicamente interno à palavra, no qual as sílabas são prosodizadas na mesma $\mathrm{PW}^{1}$, o contexto PW/PW implica já uma prosodização das duas PW no mesmo IP e, portanto, uma realização mais externa do sândi, e finalmente o contexto $\mathrm{PhP} / \mathrm{PhP}$ envolve uma fronteira prosódica alta, acima da palavra, com os dois constituintes prosódicos $\mathrm{PhP}$ integrados no mesmo IP.

Os exemplos que se seguem ilustram a produção de sândi em cada um dos contextos prosódicos analisados.

(i) $\quad \mathrm{Cl} . / \mathrm{PW}$

(13) Estão nas árvores? - ['tẽ̃̃wne' zavuli]

(Luma: 3;06)

\footnotetext{
${ }^{1}$ Vide Vigário (2003) para a prosodização dos clíticos no sistema alvo. 
(ii) $\mathrm{PW} / \mathrm{PW}$

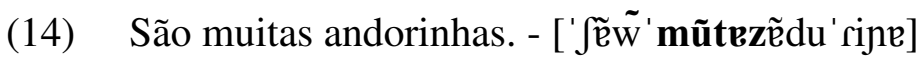

(Luma: 3;07)

(iii) $\mathrm{PhP} / \mathrm{PhP}$

(15) Pus duas coisas. - ['puz' due $\int '$ 'kojzef]

(Luma: 3;09)

\subsection{Posição final e posição medial de IP}

A figura 4 estabelece a comparação entre a produção de Codas em final de IP e em posição medial de IP. Nesta posição, as Codas são analisadas separadamente em cada um dos contextos, i.e., enquanto Codas efetivas, em contexto C\#C, e enquanto Ataques efetivos, em contexto $\mathrm{C} \# \mathrm{~V}$, uma vez que ambos apresentam comportamentos distintos.

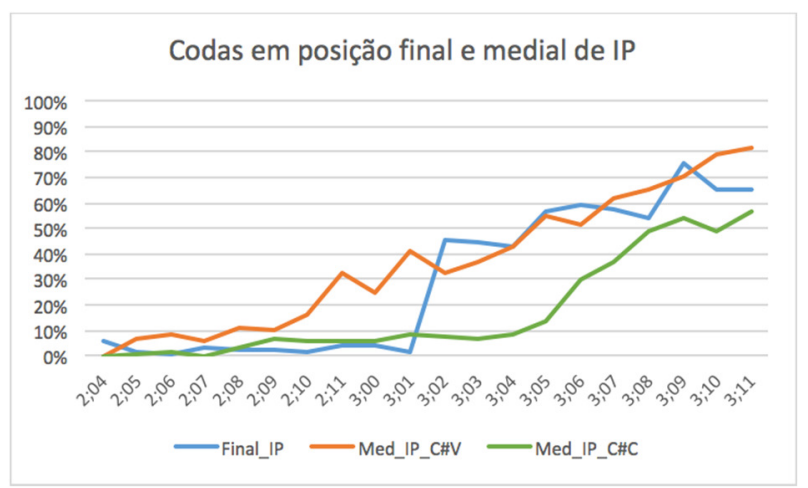

Figura 4. Desenvolvimento da produção de C em função da posição final ou interna a IP. Percentagem de ocorrência em relação à totalidade dos alvos registados em cada período.

Até aos 2;08, os valores de produção de Codas são baixos $(<10 \%)$. O contexto C\#V apresenta uma taxa de produção aproximada ao alvo mais alta até aos 3;01, momento em que a produção da Coda efetivamente emerge, em final de IP (confirmando os resultados de Jordão, 2009). Note-se que a Coda em posição medial de IP (contexto C\#C, em que temos produção efetiva de Coda) tem um desenvolvimento incipiente até cerca dos 3;05, observando-se então um incremento acentuado nas produções de acordo com alvo. 
No final do período estudado, tende-se à convergência das linhas correspondentes aos três contextos aqui analisados, apesar de esta ainda não ser obtida para a Coda em posição medial de IP.

\section{Discussão}

O fenómeno de sândi, por estar sujeito a restrições decorrentes da organização prosódica da língua, constitui uma pista para a forma como a criança e o adulto processam a componente prosódica da sua grámatica. O estudo do processo de aquisição do fenómeno de sândi, para além de apontar evidências para o domínio prosódico de IP, pode ajudar a revelar a forma como a criança vai adquirindo os vários constituintes prosódicos posicionados abaixo do IP na hierarquia prosódica.

Os dados analisados permitiram-nos compreender que, no processo de aquisição de sândi em Luma, o contexto C\#V é favorecido em relação a $\mathrm{C \# C}$, apresentando uma evolução do sândi mais precoce, independentemente do segmento em Coda (CFric, CLíq). Assim, podemos concluir que o sândi que implica não realização da Coda é adquirido primeiro e evidencia valores de produção mais elevados ao longo de todo o período estudado. $\mathrm{O}$ facto de não estar dependente da disponibilidade do constituinte silábico Coda faz com que o contexto $\mathrm{C \# V}$ conjugue as características ideais para a emergência do fenómeno de sândi externo consonântico.

Outra conclusão a que podemos chegar nesta fase do estudo é a de que a aquisição de sândi em Luma parece seguir a ordem: $\mathrm{Cl} . / \mathrm{PW}>\mathrm{PW} / \mathrm{PW}>\mathrm{PhP} / \mathrm{PhP}$. Por outras palavras, quanto mais interno na estrutura prosódica, maior é a prevalência de sândi, o que, por sua vez, pode constituir uma pista forte para o desenvolvimento da estrutura prosódica, vindo trazer evidência adicional para a "unfolding hypothesis" do desenvolvimento prosódico, proposta em Frota et al. (2016).

Recuperando as questões de investigação levantadas no início do trabalho, podemos afirmar que as primeiras produções de sândi em Luma ocorrem por volta dos 2;06, embora só a partir dos 2;09 haja produções sistemáticas. Em Luma, inicialmente, a realização de sândi é inconsistente e varia de acordo com o segmento em Coda (CFric, CLíq), com o contexto (C\#V ou C\#C) e com a fronteira prosódica em questão (16). 
(16) Quero tirar fotografias aos animais. - ['keruti 'rafutuge' fieszeni 'mazi]

Observamos, igualmente, que, no fim do período analisado, o processo de aquisição de sândi ainda não está estabilizado. A produção de sândi depende do contexto ( $\mathrm{C \# V}$ ou $\mathrm{C \# C})$, do segmento em Coda (CFric ou CLíq) e da estrutura prosódica, como se ilustra através do exemplo (17).

(17) Mami, vamos ver qual é que nós temos. - [ma'mi]IP [['vemuz' veri] [ 'kw o'le] [k'no] ['temuf]]IP (Luma: 3;11)

Assim, os resultados obtidos sobre a emergência de sândi fornecem evidência adicional para a descrição e análise de constituintes prosódicos em PE. De facto, a criança parece obedecer à restrição para a ocorrência de sândi entre IPs nas suas produções. No interior de IP, a produção de sândi varia de acordo com a fronteira prosódica onde ocorre o fenómeno, da mais interna para a mais externa, indicando que a criança vai construindo a hierarquia prosódica da língua por desdobramento dos diferentes níveis prosódicos.

\section{Conclusão}

Este trabalho tem como objetivos compreender o desenvolvimento do processo de aquisição do fenómeno de sândi externo consonântico em Luma e perceber em que medida é que ele se relaciona com a aquisição da Coda e com a estrutura prosódica.

Tendo em conta que o domínio para a realização de sândi no Português Europeu é o IP e que o sândi externo consonântico se relaciona com o constituinte silábico Coda, que pode ser realizado enquanto tal ou ressilabificado em posição de Ataque dependendo do contexto em que o sândi ocorre, as principais hipóteses desta investigação estão relacionadas com os contributos que o estudo do fenómeno pode trazer para a compreensão da forma como se desenvolve o fraseamento prosódico inicial e da forma como o sândi se relaciona com a aquisição da Coda. 
A análise das produções de Luma, compreendidas entre 2;04 e 4;00, permitiu traçar uma perspetiva longitudinal do processo de emergência e aquisição do sândi e permitiu relacioná-lo com variáveis como a idade da criança, o segmento em Coda (CFric ou CLíq), o contexto (C\#V ou C\#C) e a fronteira prosódica (Cl./PW, PW/PW ou PhP/PhP). Os dados possibilitaram, ainda, a comparação entre a aquisição da Coda em final de IP e em interior de IP.

O presente estudo conduziu à conclusão de que a aquisição do sândi externo consonântico em Luma não é um processo homogéneo e que varia de acordo com o contexto (C\#C ou C\#V), com a natureza do segmento em posição de Coda e com a estrutura prosódica. Permitiu, também, perceber que, desde o início, as produções de sândi respeitam aquilo que é esperado relativamente à gramática do adulto, uma vez que ocorrem apenas no interior de IP. Estas conclusões parecem apontar para um papel relevante da estrutura prosódica tanto na emergência dos segmentos em posição de Coda como na emergência do sândi. Tal como em Jordão (2009), os resultados deste estudo de caso sugerem que a criança organiza os enunciados em constituintes prosódicos, dado que a realização do sândi externo consonântico é condicionada pela posição que a sílaba com Coda ocupa no IP. Essa organização prosódica, aqui atestada, vem trazer novas evidências para a "unfolding hypothesis" do desenvolvimento prosódico proposta em Frota et al. (2016).

Globalmente, os resultados contribuem para compreender a relação entre a emergência do sândi e a aquisição do constituinte Coda, bem como o papel desempenhado pela estrutura prosódica em ambos os processos. Contudo, por se tratar de um estudo de caso, haverá necessidade de testar as hipóteses aqui colocadas com mais dados empíricos.

\section{Referências}

Bussmann, Hadumod, Gregory Trauth \& Kerstin Kazzazi (2000) Routledge dictionary of language and linguistics. London: Routledge.

Correia, Susana (2004) Aquisição da Rima em PE. Ditongos e Consoantes em Final de Sílaba. Dissertação de Mestrado, Universidade de Lisboa.

Freitas, Maria João (1997) Aquisição da estrutura silábica do Português Europeu. Dissertação de Doutoramento, Universidade de Lisboa. 
Frota, Sónia (2000) Prosody and focus in European Portuguese: Phonological phrasing and intonation. New York: Garland Pub.

Frota, Sónia (2014) The Intonation Phonology in European Portuguese. In Jun, S.-A. (2014) Prosodic typology II: The phonology of intonation and phrasing, Chapter 2. Oxford: Oxford University Press.

Frota, Sónia, Marina Vigário \& Raquel Jordão (2012) LumaLiDaOn (with prosodic labelling).Version 2. $\square$ Lisboa: Lab.Fonética, CLUL/FLUL. [ISLRN 371-971-843-1200].

Frota, Sónia, Marina Vigário, Nuno Matos, Marisa Cruz \& Raquel Jordão (2012) LumaLiDaAudy - Audio Child Speech Database $\square$ with phonetic transcription and prosodic labelling. Lisboa: Lab. Fonética, CLUL/FLUL. [ISLRN 433-882-165-666-8].

Frota, Sónia, Marisa Cruz, Nuno Matos \& Marina Vigário (2016) Early Prosodic Development: Emerging intonation and phrasing in European Portuguese. In M. Armstrong, N. C. Henriksen, \& M. M. Vanrell (Eds.), Intonational Grammar in Ibero-Romance: Approaches across linguistic subfields. Philadelphia, USA: John Benjamins, pp. 295324.

Jordão, Raquel (2009) A Estrutura Prosódica e a Emergência de Segmentos em Coda no PE. Um Estudo de Caso. Dissertação de Mestrado, Universidade de Lisboa.

Jordão, Raquel \& Sónia Frota (2010) The intonational phrase constrains coda development. In A. Castro, J. Costa, M. Lobo \& F. Pratas (eds.). Language Acquisition and Development. Proceedings of GALA 2009. Cambridge: Cambridge Scholars, pp. 240-251.

Ledgeway, Adam \& Martin Maiden (2016) The Oxford guide to the Romance languages. Oxford: Oxford University Press.

Peperkamp, Sharon A. (1997) Prosodic Words. The Hague: Holland Acad. Graphics.

Vigário, Marina (2003) The prosodic word in European Portuguese. Berlin: Mouton de Gruyter.

Wauquier, Sophie \& Ellenor M. Shoemaker (2013) Convergence and divergence in the acquisition of French liaison by native and non-native speakers: A review of existing data and avenues for future research. Language, Interaction and Acquisition, 4, 2, pp. 161-189. 